Trab-765-01 (6 páginas)

\title{
PRECIPITAÇÃO EFETIVA E INTERCEPTAÇÃO DAS CHUVAS POR FLORESTA DE MATA ATLÂNTICA EM UMA MICROBACIA EXPERIMENTAL EM CUNHA - SÃO PAULO ${ }^{1}$
}

\author{
Francisco Carlos Soriano Arcova 2 , Valdir de $\mathrm{Cicco}^{2}$ e Paulo Augusto Bueno Rocha ${ }^{3}$
}

\begin{abstract}
RESUMO - São apresentados os resultados de pesquisa que quantificaram a precipitação efetiva e a interceptação das chuvas pelo dossel da floresta secundária de Mata Atlântica na "microbacia experimental B", do Laboratório de Hidrologia Florestal Walter Emmerich, em Cunha-SP. No período de um ano foram medidos a precipitação no aberto, a precipitação interna e o escoamento pelo tronco das árvores, totalizando 54 coletas. Um pluviômetro em área aberta e 16 no interior da floresta foram utilizados para quantificação dos dois primeiros processos, respectivamente. Para determinação do escoamento pelo tronco foram instalados dispositivos de espuma de poliuretano em 38 árvores. A água interceptada foi estimada pela diferença entre a precipitação no aberto e a precipitação efetiva. Concluiu-se que, em média, $18,6 \%$ da precipitação foi interceptada pela floresta, retornando à atmosfera na forma de vapor. Um montante de $81,2 \%$ alcançou o piso como precipitação interna e apenas $0,2 \%$ como escoamento pelo tronco. Os fluxos de precipitação interna e escoamento pelo tronco foram maiores no período caracterizado como chuvoso. Os porcentuais de interceptação foram superiores no período pouco chuvoso.
\end{abstract}

Palavras-chave: Interceptação, precipitação interna, escoamento pelo tronco e Mata Atlântica.

\section{NET PRECIPITATION AND INTERCEPTION BY MATA ATLÂNTICA IN AN EXPERIMENTAL CATCHMENT IN CUNHA SÃO PAULO, BRAZIL}

\begin{abstract}
This paper presents data obtained from one year of measurements of gross precipitation, throughfall and stemflow in a small catchment covered with Mata Atlantica, at Walter Emmerich Forest Hydrological Laboratory, in Cunha, São Paulo, Brazil. Throughfall and stemflow under the forest were measured with sixteen rainfall gauges and thirty eight polyurethane stemflow collectors for trees in a $400 \mathrm{~m}^{2}$ experimental plot. Precipitations in a nearby clearing were collected by one rainfall gauge. Measurements were obtained in 54 storm events. Canopy interception was estimated as precipitation minus net precipitation. Total interception, throughfall and stemflow during the period were $18.6 \%, 81.2 \%$ and $0.2 \%$, respectively. Throughfall and stemflow were higher during rainy season. The percent of interception was higher during dry season.
\end{abstract}

Key words: $\quad$ Interception, throughfall, stemflow and Mata Atlântica.

\section{INTRODUÇÃO}

A cobertura florestal possui uma estreita relação com o ciclo hidrológico de uma bacia hidrográfica, interferindo no movimento da água em vários compartimentos do sistema, inclusive nas saídas para a atmosfera e para os rios.
Uma das principais influências da floresta ocorre já no recebimento das chuvas pelas copas das árvores, quando se dá o primeiro fracionamento da água, onde uma parte é temporariamente retida pela massa vegetal e em seguida evaporada para a atmosfera, processo denominado de interceptação. O restante alcança o piso como gotejamento ou precipitação interna e como fluxo que escoa pelo tronco das árvores.

1 Recebido para publicação em 14.8.2001.

Aceito para publicação em 19.2.2003.

2 Instituto Florestal de São Paulo, Caixa Postal 1322, 01059-970 São Paulo-SP. ${ }^{3}$ Estudante do Dep. de Ciências Florestais/ FCA/UNESP, Caixa Postal 237, 18603-970 Botucatu-SP. 
A soma desses dois fluxos hídricos que penetram no dossel da floresta, denominada de precipitação efetiva (Leopoldo \& Conte, 1985), é responsável pela água do solo, pela absorção através das raízes, pela transpiração das plantas e, também, pela alimentação dos rios. Por outro lado, a água evaporada das superfícies das folhas e dos ramos das copas contribui para a evapotranspiração. A interceptação da água das chuvas como componente do balanço hídrico, em regiões de regime de chuvas leves, porém contínuas e freqüentes, pode representar a maior parcela do consumo total de água por uma floresta, suplantando a transpiração pelas árvores (Lima, 1993). Conforme Lima \& Nicolielo (1983), as estimativas da evapotranspiração incorrem em erros se não for levada em conta a participação das perdas reais de interceptação, uma vez que a evaporação da água interceptada ocorre a taxas maiores que a da transpiração.

As quantidades de água envolvidas na precipitação interna, no escoamento pelo tronco e na interceptação são variáveis e dependem de fatores relacionados tanto com a vegetação quanto com as condições climáticas nas quais a floresta está inserida (Leopoldo \& Conte, 1985; Lima, 1993). Fatores experimentais também influenciam os resultados encontrados nos estudos destes processos (Castro et al., 1983), dificultando a comparação de resultados entre os locais. Em termos genéricos, pode-se dizer que em florestas tropicais de 75 a $96 \%$ da precipitação transforma-se em precipitação interna, entre 1 e $2 \%$ é convertida em escoamento pelo tronco e entre 4,5 e $24 \%$ é interceptada pelas copas das árvores (Bruijnzeel, 1990).

Não são muitas as informações sobre a repartição das chuvas por floresta de Mata Atlântica. Coelho Netto et al. (1986) estudaram o processo no Maciço da Tijuca, no Rio de Janeiro. Em reflorestamento com espécies nativas da região, determinaram a precipitação interna média como sendo equivalente a $88,6 \%$ da precipitação total. Os fluxos de escoamento pelo tronco não foram medidos e a interceptação foi estimada em 11,4\%. Em estudo com amostragem simplificada, Timoni (1992) mediu a precipitação interna em duas condições de floresta na região de Cubatão, em São Paulo. Para floresta degradada por poluição atmosférica obteve $72,1 \%$ de precipitação interna. Em vegetação preservada o valor diminuiu para $65,5 \%$. Ainda em Cubatão, em estudo mais detalhado, Nalon \& Vellardi (1992) obtiveram o elevado valor de $91,1 \%$ para precipitação interna. O escoamento pelo tronco foi reduzido, correspondendo a apenas $0,3 \%$, e as perdas anuais por interceptação foram calculadas

R. Árvore, Viçosa-MG, v.27, n.2, p.257-262, 2003 em 8,6\%. Na Ilha do Mel, no Paraná, Britez et al. (1998) mediram a precipitação interna em duas formações de vegetação: floresta seca e floresta paludosa. Em dois anos de pesquisa obtiveram precipitação interna que correspondeu a 77 e $79 \%$ para o primeiro tipo de floresta e 64 e $76 \%$ para o segundo. $\mathrm{O}$ escoamento pelo tronco não foi medido, e os autores estimaram as perdas por interceptação em floresta seca como sendo de 23 e $21 \%$ e entre 36 e $24 \%$ para floresta paludosa. Na "microbacia experimental D" do Laboratório de Hidrologia Florestal Walter Emmerich, em Cunha, São Paulo, Cicco et al. (1986/88) encontraram valores de precipitação interna, escoamento pelo tronco e interceptação iguais a 80,7, 1,1 e $18,2 \%$, respectivamente.

O objetivo da presente pesquisa foi estudar a repartição das águas de chuva pela Mata Atlântica através dos processos de precipitação interna e escoamento pelo tronco, como também a quantificação da interceptação. $\mathrm{O}$ estudo dá continuidade ao detalhamento do balanço hídrico da "microbacia experimental B" (Arcova, 1996; Fujieda et al., 1997).

\section{MATERIAIS E MÉTODOS}

\section{1. Área de Estudo}

O estudo foi desenvolvido na "microbacia experimental B" do Laboratório de Hidrologia Florestal Walter Emmerich, instalado no Núcleo Cunha do Parque Estadual da Serra do Mar, a leste do Estado de São Paulo. As coordenadas geográficas do local são $23^{\circ} 13^{\prime}$ a $23^{\circ}$ $16^{\prime}$ de latitude sul e $45^{\circ} 03^{\prime}$ a $45^{\circ} 05^{\prime}$ de longitude oeste.

A microbacia está a uma altitude de $1.050 \mathrm{~m}$ e tem uma área de 36,68 ha. Latossolos e Cambissolos Álicos são os solos predominantes. Leitão Filho (1982) classificou a vegetação natural primária da região como Floresta Latifoliada Perenifólia - Mata Atlântica. A microbacia encontra-se recoberta por vegetação secundária, resultado de exploração madeireira ocorrida no passado. Há mais de 45 anos ocorre o processo de regenaração da floresta, sem qualquer intervenção antrópica. Na porção mais elevada e de maior declividade encontram-se árvores remanescentes da vegetação primitiva, que podem alcançar $20 \mathrm{~m}$ de altura. No restante da bacia raramente as árvores ultrapassam este porte. No levantamento florístico conduzido na "microbacia experimental D", localizada a $3 \mathrm{~km}$ da área em estudo, foram amostradas 102 espécies arbóreas e, ou, arbustivas 
pertencentes a 65 gêneros e 38 famílias, das quais se destacam Myrtaceae, Lauraceae, Solonaceae, Asteraceae e Melastomataceae. Os gêneros mais importantes são Ocotea, Solanum e Miconia (Arcova, 1996).

Massas de ar equatoriais e tropicais imprimem à área uma dinâmica climática caracterizada por um clima úmido, com fortes influências da altitude e dos efeitos orográficos da Serra do Mar (Furian, 1987). A precipitação média anual é de $2.240 \mathrm{~mm}$, distribuídos em um período chuvoso ou úmido (outubro a março) e um período pouco chuvoso ou pouco úmido (de abril a setembro). Os tipos de precipitação da área são distintos, em função da época do ano. As chuvas no período úmido são freqüentemente fortes e podem estar associadas a trovoadas, enquanto na estação pouco úmida ocorrem chuvas uniformes que podem se estender por todo o dia (Jica, 1986). A temperatura média anual é de $16,5^{\circ} \mathrm{C}$ e a umidade relativa do ar de $79 \%$, conforme dados obtidos na estação meteorológica local.

\subsection{Metodologia}

Para o estudo dos componentes da repartição das chuvas pela floresta foi instalada uma parcela de $400 \mathrm{~m}^{2}$, representativa da microbacia em relação à sua cobertura vegetal, e localizada em terreno pouco acidentado, com declividade média de $10 \%$.

$\mathrm{Na}$ quantificação da precipitação interna foram empregados 16 pluviômetros, distribuídos aleatoriamente na parcela e mantidos fixos ao longo do período experimental.

A água de escoamento pelo tronco das árvores foi coletada por intermédio de dispositivos confeccionados com espuma de poliuretano, conforme metodologia proposta por Likens \& Eaton (1970), os quais foram instalados em todas as árvores da parcela com DAP igual ou superior a $10 \mathrm{~cm}$, totalizando 38 indivíduos.

A precipitação no aberto foi medida utilizando um pluviômetro, instalado numa clareira com trinta metros de diâmetro, localizada a duzentos metros da parcela experimental.

A interceptação foi obtida a partir da diferença entre a precipitação efetiva e a precipitação no aberto. A precipitação interna correspondeu à média aritmética das quantidades de chuva nos dezesseis pluviômetros. A quantidade de água escoada pelo tronco das árvores da parcela foi determinada a partir da somatória do escoamento pelo tronco das trinta e oito árvores, com a conversão do volume de água de litros (1) para milímetros de altura da água $(\mathrm{mm})$ feita em relação à área da parcela, conforme LIMA (1986).

Cada coleta constituiu-se de uma ou mais precipitações.

\section{RESULTADOS E DISCUSSÃO}

Obteve-se grande amplitude de variação da precipitação no aberto, com extremos de 2,8 e 197,7 mm em 54 coletas. O total precipitado no período foi de $2.220 \mathrm{~mm}$, sendo representativo da precipitação anual do local. Esse valor é intermediário aos índices pluviométricos mínimo e máximo medidos no Laboratório de Hidrologia Florestal Walter Emmerich, isto é, 1.815 e $3.088 \mathrm{~mm}$, e é praticamente idêntico à precipitação média anual, que é de $2.240 \mathrm{~mm}$ (Arcova,1996).

Como o processo de fracionamento da água das chuvas pela floresta é influenciado pelas condições das precipitações, optou-se por agrupar e analisar os resultados nos dois períodos distintos do ano que caracterizam as chuvas no laboratório, isto é, períodos chuvoso e pouco chuvoso. Os dados de precipitação no aberto e da precipitação interna, do escoamento pelo tronco e da interceptação foram submetidos à análise de regressão linear, cujos resultados estão na Figura 1.

A precipitação interna e o escoamento pelo tronco apresentaram elevada relação com a quantidade da precipitação no aberto, com o menor valor do coeficiente de determinação $\left(\mathrm{R}^{2}\right)$ de 0,8046 . A interceptação, por sua vez, apresentou elevada relação com a precipitação no aberto no período pouco chuvoso, porém relativamente baixa no período das chuvas, com $\mathrm{R}^{2}$ igual a 0,5806 .

As curvas de tendência dos fluxos de água que penetram o dossel florestal no período úmido suplantaram as curvas do período pouco úmido, indicando um comportamento distinto das duas frações em função da época do ano. Entre outubro e março os valores de precipitação interna e de escoamento pelo tronco tenderam a ser maiores que no resto do ano.

As perdas por interceptação entre os dois períodos foram diferenciadas, com tendência de maiores valores no período pouco úmido. Este comportamento deve ser resultado, dentre outros fatores, das características distintas das chuvas locais que ocorrem nas duas épocas do ano. Entre abril e setembro as chuvas são normalmente

R. Árvore, Viçosa-MG, v.27, n.2, p.257-262, 2003 
contínuas e pouco intensas, circunstâncias nas quais a interceptação pode alcançar seu valor máximo. As diferenças na interceptação entre períodos de chuvas foram verificadas também por Coelho Netto et al. (1986) e Nalon \& Vellardi (1992).
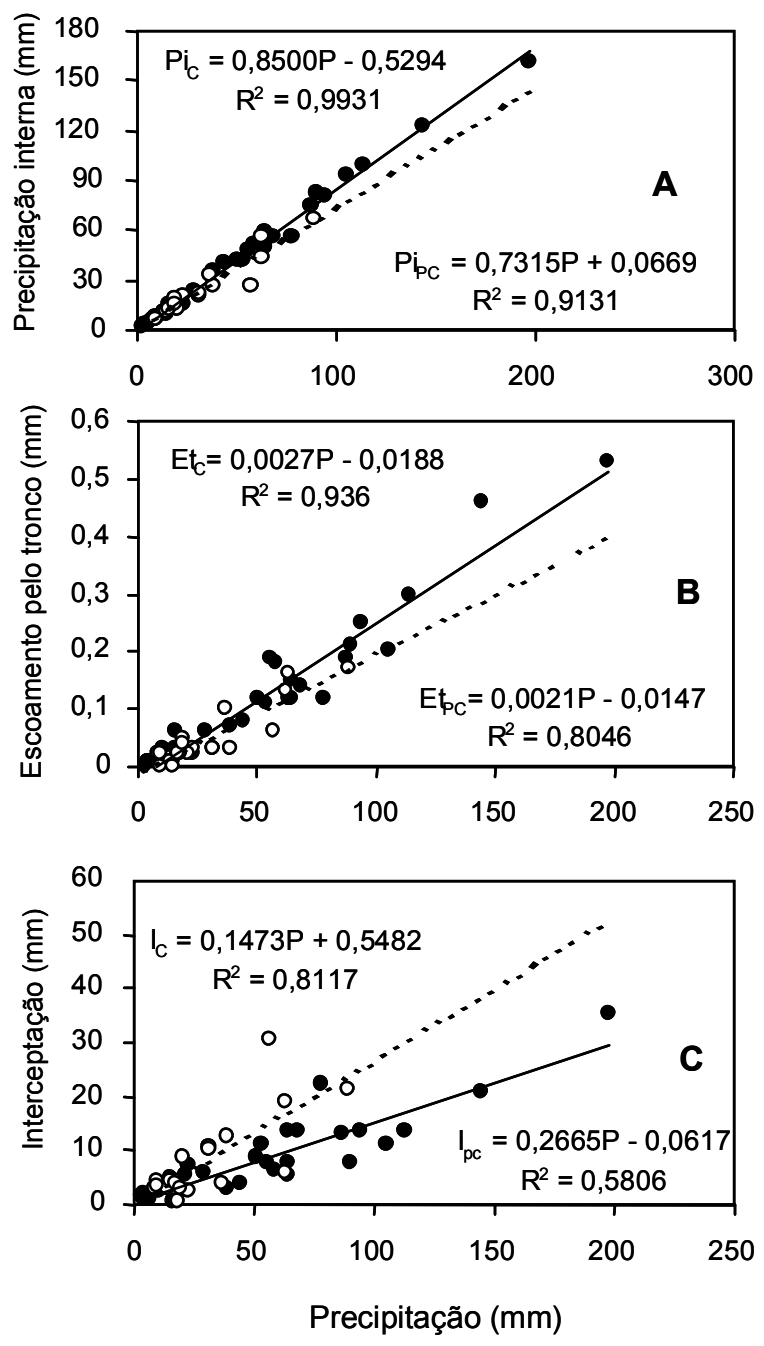

- Período chuvoso (c) o Período pouco chuvoso (pc)

Figura 1 - Relação entre a precipitação e a precipitação interna (A), o escoamento pelo tronco (B) e a interceptação (C), para os períodos chuvoso (c) e pouco chuvoso (pc) Microbacia "B" do Laboratório de Hidrologia Floresal Walter Emmerich, Chunha-SP. Período de 20 de novembro de 1997 a 20 de novembro de 1998.

Figure 1 -Relationship between precipitation and throughfall (A), stemflow (B) and interception (C), for rainy season (c) and dry season ( $p c)$ - Catchment " $B$ " in the Walter Emmerich Forest Hydrological Laboratory, Cunha, Brazil. From 20 November 1997 to 20 November 1998.

R. Árvore, Viçosa-MG, v.27, n.2, p.257-262, 2003
No Quadro 1 estão os resultados da repartição das chuvas nas três frações para cada mês, assim como os respectivos totais anuais.

Quadro 1 - Valores mensais e anuais de precipitação (P), precipitação interna (Pi), escoamento pelo tronco (Et), precipitação efetiva (Pe) e interceptação (I) Microbacia "B" do Laboratório de Hidrologia Florestal Walter Emmerich, Chunha-SP. Período de 20 de novembro de 1997 a 20 de novembro de 1998

Table 1 - Monthly and annual values of precipitation $(P)$, throughfall (Pi), stemflow (Et), net precipitation (Pe) and interceptation (I) - Catchment " $B$ " in the Walter Emmerich Forest Hydrological Laboratory, Cunha, Brazil. From 20 November 1997 to 20 November 1998

\begin{tabular}{|l|r|r|r|r|r|r|r|r|r|r|}
\hline \multirow{2}{*}{ Mês } & \multicolumn{1}{|c|}{$\mathrm{P}$} & \multicolumn{1}{|c|}{$\mathrm{Pi}$} & $\mathrm{Et}$ & \multicolumn{1}{c|}{$\mathrm{Pe}$} & \multicolumn{1}{c|}{$\mathrm{I}$} & $\mathrm{Pi}$ & $\mathrm{Et}$ & $\mathrm{Pe}$ & $\mathrm{I}$ \\
\cline { 2 - 11 } & \multicolumn{9}{|c|}{$(\mathrm{mm})$} \\
\hline Dez. & 157,1 & 130,1 & 0,33 & 130,43 & 26,67 & 82,8 & 0,2 & 83,0 & 17,0 \\
\hline Jan. & 355,2 & 304,7 & 0,95 & 305,65 & 49,55 & 85,8 & 0,3 & 86,1 & 13,9 \\
\hline Fev. & 371,4 & 301,1 & 0,87 & 301,97 & 69,43 & 81,1 & 0,2 & 81,3 & 18,7 \\
\hline Mar. & 268,3 & 236,7 & 0,68 & 237,38 & 30,92 & 88,2 & 0,3 & 88,5 & 11,5 \\
\hline Abr. & 108,1 & 81,1 & 0,22 & 81,32 & 26,78 & 75,0 & 0,2 & 75,2 & 24,8 \\
\hline Mai. & 120,0 & 85,2 & 0,21 & 85,41 & 34,59 & 71,0 & 0,2 & 71,2 & 28,8 \\
\hline Jun. & 88,4 & 47,4 & 0,09 & 47,49 & 40,91 & 53,6 & 0,1 & 53,7 & 46,3 \\
\hline Jul. & 49,8 & 35,0 & 0,05 & 35,05 & 14,75 & 70,3 & 0,1 & 70,4 & 29,6 \\
\hline Ago. & 25,0 & 17,4 & 0 & 17,40 & 7,60 & 69,6 & 0 & 69,6 & 30,4 \\
\hline Set. & 193,4 & 163,0 & 0,37 & 163,37 & 30,03 & 84,3 & 0,2 & 84,5 & 15,5 \\
\hline Out. & 289,9 & 243,7 & 0,65 & 244,35 & 45,55 & 84,3 & 0,2 & 84,3 & 15,7 \\
\hline Nov. & 193,7 & 157,5 & 0,35 & 157,85 & 35,85 & 81,3 & 0,2 & 81,5 & 18,5 \\
\hline Total & $2.220,3$ & $1.802,9$ & 4,77 & $1.807,67$ & 412,63 & 81,2 & 0,2 & 81,4 & 18,6 \\
\hline
\end{tabular}

No período chuvoso, a precipitação que efetivamente alcançou o piso da floresta foi da ordem de $85 \%$ da precipitação incidente na área. No período pouco chuvoso, a penetração das chuvas no dossel foi menor, em média $72 \%$ da precipitação. No caso extremo somente $53,7 \%$ das chuvas transpassaram as copas. A água chegou ao piso majoritariamente pela precipitação interna; o escoamento pelo tronco não ultrapassou $0,3 \%$ da precipitação no aberto.

Quanto à interceptação, os porcentuais foram elevados na estação pouco úmida, com valor médio estimado em $26 \%$ da precipitação no aberto. Na estação das chuvas os porcentuais foram reduzidos, sendo a média de apenas $16 \%$.

Em termos anuais, a contribuição do fluxo de água escoado pelo tronco das árvores para a precipitação efetiva foi de apenas $4,8 \mathrm{~mm}$, sendo desprezível quando 
comparada com a participação da precipitação interna, isto é, de $1.802,9 \mathrm{~mm}$. A interceptação de $412 \mathrm{~mm}$ é um valor significativo, uma vez que a evapotranspiração anual na "microbacia B", medida pelo método do balanço hídrico, é da ordem de 539 +/- 100 mm (Arcova, 1996), o que indica que a interceptação tem grande importância na composição das perdas evaporativas da microbacia.

Os porcentuais médios de precipitação interna, escoamento pelo tronco e interceptação em relação à precipitação no aberto, registrados "na microbacia B", são intermediários aos encontrados nos estudos desenvolvidos em Mata Atlântica. Diferenças climáticas, de características da vegetação e metodológicas são fatores que contribuem para este comportamento (Bruijnzeel, 1990). Porém, tal fato não é verificado quando os resultados são comparados com aqueles obtidos por Cicco et al. (1986/88), em pesquisa realizada na "microbacia experimental D", vizinha à "microbacia B". Os valores de precipitação interna e interceptação são muito próximos, da ordem de 81 e $18 \%$, respectivamente. A similaridade dos resultados deve-se à homogeneidade climática e da tipologia da vegetação nas microbacias. Quanto ao escoamento pelo tronco, a despeito dos valores reduzidos alcançados nas duas pesquisas, certamente os resultados do presente trabalho são mais consistentes, uma vez que quando da amostragem desse fluxo de água foram realizadas coletas em todas as árvores da parcela, enquanto na ocasião do primeiro estudo apenas oito árvores foram amostradas, sendo feita a extrapolação para toda a parcela.

Os resultados obtidos neste artigo reforçam a necessidade de continuidade dos estudos sobre o ambiente de Mata Atlântica, pois possuem um relevante papel conservacionista.

\section{CONCLUSÕES}

Em média, 18,6\% da precipitação foi interceptada pela floresta secundária de Mata Atlântica da "microbacia B", retornando à atmosfera na forma de vapor. Um montante de $81,2 \%$ alcançou o piso como precipitação interna e apenas $0,2 \%$ como escoamento pelo tronco das árvores. Os resultados são consistentes com os obtidos em pesquisa anteriormente desenvolvida na região.

Os fluxos de precipitação interna e escoamento pelo tronco foram maiores no período caracterizado como chuvoso. Os porcentuais de interceptação foram maiores no período pouco chuvoso.

\section{AGRADECIMENTO}

Aos senhores João Batista Amaro dos Santos e Ivail R. de Toledo, funcionários do Laboratório de Hidrologia Florestal Walter Emmerich, pelo auxílio na instalação de equipamentos e na realização das coletas.

\section{REFERÊNCIAS BIBLIOGRÁFICAS}

ARCOVA, F. C. S. Balanço hídrico, características do deflúvio e calibragem de duas microbacias hidrográficas na Serra do Mar, SP. Piracicaba: Escola Superior de Agricultura "Luiz de Queiroz", 1996. 130 p. Dissertação (Mestrado em Ciências Florestais). Escola Superior de Agricultura "Luiz de Queiroz”, 1996.

BRITEZ, R. M. et al. Interceptação das chuvas em duas formações florestais da planície litorânea da Ilha do Mel, PR. In: FÓRUM DE GEOBIOHIDROLOGIA, 1., 1998, Curitiba. Anais... Curitiba: Universidade Federal do Paraná, 1998. p. 60-69.

BRUIJNZEEL, L. A. The hydrological cycle in moist tropical forest. In: BRUIJNZEEL, L. A. Hydrology of moist tropical forests and effects of conversion: a state of knowledge review. Amsterdam: IAHS, 1990. p. 5-38.

CASTRO, P. S. et al. Interceptação da chuva por mata natural secundária na região de Viçosa, MG. Revista Árvore, v. 7, n. 1, p. 76-89, 1983.

CICCO, V. et al. Interceptação das chuvas por floresta natural secundária de Mata Atlântica - São Paulo.

Silvicultura em São Paulo, v. 20/22, p. 25-30, 1986/88.

COELHO NETTO, A. L.; SANCHE, M.; PEIXOTO, M. N. O. Precipitação e interceptação florestal em ambiente tropical montanhoso, Rio de Janeiro. Revista Brasileira de Engenharia, v. 4, n. 2, p. 55-71, 1986.

FUJIEDA, M. et al. Hydrological processes at two subtropical forest catchments: the Serra do Mar, São Paulo, Brazil. Journal of Hydrology, v. 196, p. 26-46, 1997.

FURIAN, S. M. Estudo geomorfológico do escoamento superficial em parcelas experimentais no Parque Estadual da Serra do Mar - Núcleo Cunha / SP. Um esboço metodológico. São Paulo: Faculdade de Filosofia, Letras e Ciências Humanas, 1987. 187 p. Dissertação (Mestrado em Geografia). Faculdade de Filosofia, Letras e Ciências Humanas, 1987.

R. Árvore, Viçosa-MG, v.27, n.2, p.257-262, 2003 
JAPAN INTERNATIONAL COOPERATION AGENCYJICA. Synthetic report of the Japanese technical cooperation project for forestry research in São Paulo, Brazil. S.1.: 1986. 555 p.

LEITÃO FILHO, H. F. Aspectos taxonômicos das florestas do Estado de São Paulo. In: CONGRESSO NACIONAL SOBRE ESSENCIAS NATIVAS, 1., 1982, Campos do Jordão. Anais... São Paulo: 1982. Silvicultura em São Paulo, v. 16 A. p. 197-206. (Edição Especial)

LEOPOLDO, P. R.; CONTE, M. L. Repartição da água de chuva em cobertura vegetal com características de cerradão. In: SIMPÓSIO BRASILEIRO DE HIDROLOGIA E RECURSOS HÍDRICOS E SIMPÓSIO INTERNACIONAL DE RECURSOS HÍDRICOS EM REGIÕES

METROPOLITANAS, 6., 1985, São Paulo. Anais... São Paulo: ABRH, 1985. v. 3. p. 212-220.

LIKENS, G. E.; EATON, J. S. A polyurethane stemflow collector for trees and shrubs. Ecology, v. 51, n. 5, p. 938939, 1970.
LIMA, W. P. Interceptação. In: LIMA, W.P. Princípios de hidrologia florestal para o manejo de bacias hidrográficas. São Paulo: Universidade de São Paulo, 1986. p. 87-101.

LIMA, W. P. Hidrologia de plantações de eucaliptos. In: LIMA, W.P. Impacto ambiental do eucalipto. São Paulo: Universidade de São Paulo, 1993. p. 51-137.

LIMA, W. P.; NICOLIELO, N. Precipitação efetiva e interceptação em florestas de pinheiros tropicais e em reserva de cerradão. IPEF, n. 24, p. 43-46, 1983.

NALON, M. A.; VELLARDI, A. C. V. Interceptação na floresta secundária das encostas da Serra do Mar, região de Cubatão, SP. In: CONGRESSO NACIONAL SOBRE ESSÊNCIAS NATIVAS, 2., 1992, São Paulo. Anais... São Paulo: 1992. Revista do Instituto Florestal, v. 4, p. 894-899. (Edição Especial)

TIMONI, J. L. Alterações nos ciclos naturais: o caso Cubatão. In: CONGRESSO NACIONAL SOBRE ESSÊNCIAS NATIVAS, 2, 1992, São Paulo. Anais... São Paulo: 1992; Revista do Instituto Florestal, v. 4, p. 743-747. 